\title{
Sources and Consequences of Athletic Burnout Among College Athletes
}

\author{
Daniel Gould and Meredith A. Whitley \\ Michigan State University
}

\begin{abstract}
It has been shown that it takes 10 years or 10,000 hours of deliberate practice to develop one's talent in any field, including athletics (Ericsson, 1996). Given the amount of time, sacrifice, and effort needed to become an expert athlete, it is not surprising that researchers have been interested in examining burnout in competitive athletes (see: Cresswell \& Eklund, 2006; Goodger, Gorely, Lavalle, \& Harwood, 2007; Gould \& Dieffenbach, 2002, for detailed reviews). While burnout has been defined in several ways, it can generally be viewed as a physical, social, and emotional withdrawal from a formerly enjoyable activity as a result of chronic stress and motivation concerns that is typically characterized by feelings of emotional exhaustion, reduced accomplishment, and depersonalization/devaluation. In this review, research and theories on burnout in athletes are examined for the purposes of identifying sources of and consequences of burnout in collegiate athletes. Future research directions are identified as well as implications for protecting the health and welfare of student athletes.
\end{abstract}

For close to a century, athletics has been part of the fabric of American higher education. It has been incorporated as an extracurricular activity on college campuses with the belief that participation contributes to the total educational development of the student-athlete. This emphasis on educational development is highlighted by the National Collegiate Athletic Association (NCAA), which states that their purpose is "to integrate intercollegiate athletics into higher education so that the educational experience of the student-athlete is paramount" (NCAA, 2007). The assumption is that participation not only provides an enjoyable and healthy release for students but also teaches a variety of skills that may not be taught in other settings, such as teamwork and leadership.

According to the NCAA and other sources, the intent of intercollegiate athletics is educational; however, it has become increasingly commercialized. The drive for collegiate programs to garner publicity and attain notoriety at the local, regional, and, at times, national levels has increased; similarly, the opportunities to achieve this publicity and notoriety have grown as well, particularly when individual athletes and teams are considered to be successful. With this increased emphasis placed on success, program costs have escalated, leading to a funda-

The authors are with the Institute for the Study of Youth Sports, Michigan State University, 210 IM Sports Circle, East Lansing, MI, 48824-1049. 
mental shift in the focus of collegiate programs: the importance of the athlete's educational development has slowly diminished while the focus on winning has largely become the primary concern. In response to these changes, the NCAA has tried to maintain the educational perspective in college sports by passing and enforcing key regulations, including a requirement of academic progress toward degrees, a limitation on the number of hours that athletes can train and compete, and the provision of a variety of support services for student-athletes.

This fundamental shift toward the high valuation of success is not limited to the overall mindset of the most elite collegiate programs, as Bowen and Levin (2003) have demonstrated that student-athletes from all NCAA Divisions are taking a more professionalized approach to their sport, even when athletic scholarships are not involved. Not surprisingly, this professionalized approach toward sport does not miraculously appear at the college level, as younger athletes have shifted toward a professional mindset as well. Unlike past generations, athletes now train for years to hone their athletic talents, with the ultimate goal of playing college athletics. Research has suggested that it takes 10 years or 10,000 hours of deliberate practice to develop one's talent to the level of "expert" in any field, including that of athletics (Ericsson, 1996). If an athlete wants to reach this level of expertise during college, he or she will need to give an extraordinary amount of time, sacrifice, and effort during his or her childhood, adolescence, and collegiate years.

As the professionalization of sport has steadily increased at the collegiate level, it is not surprising that researchers have been interested in examining burnout in athletes, particularly those who are highly competitive and involved in their sport (see: Cresswell \& Eklund, 2006; Goodger, Gorely, Lavalle, \& Harwood, 2007; and Gould \& Dieffenbach, 2002, for detailed reviews). A principal concern in these research studies has been the question of how burnout affects the health and life satisfaction of athletes. To insure that student-athletes pursue athletic excellence in a safe and healthy environment, it is important to understand burnout in student-athletes. This review is designed to do so. In it, we will provide a definition of burnout, examine existing models of sport burnout, and identify the sources and consequences of burnout. We will emphasize the implications for preventing burnout and for protecting the health and welfare of student-athletes.

\section{Defining Burnout and Burnout-Related Terms}

Burnout has been defined in several ways in sport science literature. The earliest definition was by psychologist Ron Smith (1986), who looked at burnout from a stress perspective. He believed that athletes burnout of sport as a result of chronic stress. By experiencing stress over time, an activity (sport) that was perceived as enjoyable in the past becomes no longer enjoyable. This leads to a physical, psychological, and/or social withdrawal from their sport. In contrast, Raedeke (1997) focused on the manifestation of burnout, indicating that burnout is a psychological syndrome that is characterized by emotional/physical exhaustion, a reduced sense of accomplishment, and the devaluation of one's sport involvement. Other investigators have viewed burnout from a motivational perspective, where certain motivational factors cause athletes to lose their passion for involvement 
(Cresswell \& Eklund, 2005a, 2005b, 2005c; Lemyre, Roberts, \& Stray-Gundersen, 2007; Perreault, Gadreau, Lapointe, \& Lacroix, 2007; Raedeke, 1997).

Clearly, there is no one universally accepted definition of athlete burnout; however, it is likely that burnout involves elements of all of these definitions, and that it is a process that unfolds over time. For the purpose of this review, burnout will be defined as a physical, emotional, and social withdrawal from a formerly enjoyable sport activity. This withdrawal is characterized by emotional and physical exhaustion, reduced sense of accomplishment, and sport devaluation. Moreover, burnout occurs as a result of chronic stress (a perceived or actual imbalance between what is expected of an athlete physically, psychological, and socially and his or her response capabilities) and motivational orientations and changes in the athlete.

There are several other terms coming out of the physical training literature that are associated with burnout. These include overloading, overtraining, overreaching, and staleness (Weinberg \& Gould, 2007). As part of a normal course of physical training, coaches are taught to overload their athletes (giving them more training volume than they are accustomed to) followed by a period of rest where the body adapts to the increased load. This process of increasing the training load and then allowing a period of recovery takes place over time, and the athlete is able to improve his or her physical conditioning. Unfortunately, overtraining can occur if the training loads are too high or the recovery periods are inadequate. This process of overtraining is highly individualistic, meaning that each athlete has optimal training loads and recovery periods. If overtraining does occur, the athlete could experience "staleness," which is a physiological state of overtraining that results in deteriorated performance (American Medical Association, 1966). It is thought that if short-term states of staleness are not addressed with adequate recovery over time, they can lead to full-blown burnout (Kentta, 2001).

\section{Models of Burnout in Athletes}

As investigators have studied burnout in athletes, several models and theories have emerged as a means to guide and explain the researchers' efforts to understand this phenomenon. These include Smith's (1986) congnitive-affective stress model, Coakley's (1992) unidimensional identity development and external control model, Silva's (1990) and Kentta and Hassmen's (2001) negative training stress response models, and several motivational theories (Raedeke's [1997] entrapment, Cresswell \& Eklund's [2005a, 2005b, 2005c, 2007a, 2007b] recent applications of self-determination theory, and Lonsdale, Hodge, \& Jackson's [2007] engagement approach). Each of these will be briefly discussed below.

\section{The Congnitive-Affective Stress Model}

In his original article that drew attention to the need for sport psychologists to study athlete burnout, psychologist Ron Smith (1986) adopted a stress-based approach to understanding burnout in sport. Consistent with theories of stress, Smith conceptualized burnout as a process that involves four stages: situational demands; cognitive appraisal; physiological responses; and behavioral responses. The process unfolds when an athlete faces some "situational demands," such as 
high training volume and/or intensity and high expectations for success. The second stage of the process involves the individual's "cognitive appraisal" of the situation, when the athlete determines whether the demands of the situation outweigh his or her resources. This phase is thought to be influenced by a variety of personality and motivational factors, such as trait anxiety, goal orientations, and perfectionism. If the athlete perceives that the situational demands outweigh his or her resources, he or she will experience "physiological responses," such as changes in tension, insomnia, fatigue, and anxiety. The final phase of the cognitive -affective stress model is the "behavioral response" of the athlete. This consists of certain task behaviors and coping responses, including decreased performance and withdrawal from activities.

To give a vivid example of this model, imagine a sophomore collegiate crosscountry runner who trains rigorously all summer in an attempt to live up to the success that she achieved during her freshman year. Being a highly perfectionistic but low confidence individual, she cognitively appraises the situational demands to outweigh her capabilities. This results in the decision to continue to overtrain for the entire year, including running outside of her normal team practices. Constantly worrying about living up to everyone else's and her own expectations, our runner feels anxious, has trouble sleeping, and feels fatigued. As the season progresses and the chronic stress persists, this results in certain coping and task behaviors in our runner, such as decreased performance (because of the fatigue, insomnia, overtraining, and anxiety) and emotional withdrawal from her sport, along with motivational struggles and reduced satisfaction from her involvement.

Because it is so broad, Smith's (1986) cognitive-affective stress model is quite difficult to directly test. However, in some of the original junior tennis research conducted by Gould, Tuffey, Udry, and Loehr (1996, 1997), it was concluded that Smith's model provided a good explanation for the cases of burnout examined. Furthermore, recent case study research by Cresswell and Eklund (2007b) and Gustafsson, Kentta, Hassmen, Lindquist, and Durand-Bush (2007) have shown that stress is highly involved in the burnout process, providing further support for the cognitive-affective stress model.

\section{Unidimensional Identity Development and External Control Model}

In 1992, sport sociologist Jay Coakley offered an alternative view to the physical and psychological stress models of burnout. Coakley (1992) contended that although stress is certainly involved in athlete burnout, it was not the cause. Coakley believed that stress was actually a symptom of burnout. For him, the real cause of burnout, especially in young people involved in high performance sports, was more sociological in nature. Specifically, it was suggested that burnout occurs because of the way sport is structured in our society. Organized sport is structured in a way that minimizes the personal control that young people have in decision making. In addition, the structure of high performance sport in contemporary society often constricts the development of normal identities for young people. Young athletes are socialized to focus almost exclusively on sporting success, leading to a sport-centered identity that minimizes the opportunity to develop 
other sources of identity. With this sport-centered mindset, the inability to reach one's goals in sport (e.g., injury, losing) can lead to increased levels of stress and, eventually, burnout. According to Coakley, further stress and burnout are caused by the fact that young people make few real decisions in the sport process. In this view, stress is not the cause of burnout in young athletes; instead, it is the social organization of high performance sport that is the primary cause.

Coakley (1992) based his original model on interviews that he conducted with a number of young athletes. Gould and his colleagues (1997) provided some support for Coakley's contentions in qualitative interviews with junior tennis players. However, these were not direct tests. More recently, Black and Smith (2007) directly tested Coakley's contentions that restricted opportunities to make decisions, externally controlled sport decisions, and a narrow identity cause burnout in 182 swimmers ages 13-22. Hierarchical regression results provided some support for Coakley's beliefs, revealing that the exclusivity of athletic identity and the perceived control over swimming contributed 3 and $13 \%$ of variance in the burnout subscale scores over and above stress and performance indices. However, the exclusivity of athletic identity findings were the opposite of the predictions, and the identity and control measures did not moderate the stress and burnout dimensions. Like most quantitative studies of burnout, the study was limited by the fact that most athletes were relatively healthy and did not score high on burnout measures.

\section{Negative Training Stress Models}

One of earliest models of burnout was presented by Silva (1990). It was Silva's view that physical training causes stress for the athlete on a physical level and a psychological level. This stress can have both positive and negative effects. According to Silva, burnout occurs when training volumes are too high, too intense, and lead to negative adaptation. If this persists, it can lead to staleness and, eventually, burnout. Initially, little research was spurred by Silva's model, but over the last decade, Swedish researchers, lead by Goran Kentta and his colleagues (Kentta, 2001; Kentta \& Hassmen, 1998; Kentta, Hassmen, \& Raglin, 2001), have extensively studied physical training and recovery in athletes as it relates to burnout. Specifically, Kentta (2001) has suggested that as a normal part of physical training, athletes overload themselves (overtrain), which then leads to an overreached state. This process of overtraining is highly individualistic, meaning that the amount of physical training that results in overtraining will vary from one athlete to another. If an athlete reaches the overreach state, this is not necessarily negative, because with proper rest, the body will compensate and physical improvement will occur. However, negative overtraining occurs when the physical demands are excessive and the body does not adapt properly. This leads to staleness in the athlete, and, if adequate rest and recovery does not occur, burnout will develop. Thus, this model suggests that burnout is the end product of a physical training process gone array.

Overall, the research by Kentta and his colleagues (Kentta \& Hassmen, 1998; Kentta et al., 2001) demonstrates that physical training is certainly involved in the burnout process. However, it is not just a matter of physical overtraining. Recent evidence shows that the intensity of training must be considered, along with a 
variety of psychological and social stressors and recovery factors. This suggests that burnout needs to be approached from a multivariate perspective.

\section{Motivational Models}

While researchers initially interested in burnout focused their attention on stress, the social structure of high performance sport, and physical overtraining as causes, in the last decade, there has been considerable interest in motivational models as explanations for burnout. A number of these models are outlined below.

The entrapment view. Raedeke (1997) put forth the first motivational model when he drew on Schmidt and Stein's (1991) sport commitment theorizing to form his view of burnout as sport entrapment. This entrapment model holds that athletes have three reasons for committing to sport: (1) the athlete wants to; (2) the athlete believes that he or she has to; or (3) a combination of both reasons. Raedeke contends that athletes who feel entrapped, believe that they "have to" participate in sport, are prone to burnout. These entrapped athletes often maintain their involvement in sport despite not wanting to participate for several reasons. First, it is possible that these athletes lack alternatives to sport. Second, they may feel like they cannot discontinue involvement because they have invested too much time and energy to stop. Finally, the athlete's self-identity may be tied to athletics in such a way that they would feel personally lost if they discontinued. One example of this would be collegiate athletes with a scholarship, who might feel entrapped in their sport because the decision to discontinue their involvement would result in a loss of their university scholarship.

Raedeke (1997) tested his contentions in a study with 200 adolescent swimmers. He found that some swimmers did feel entrapped in their sport, because they were no longer interested in participating but believed that they had to. Results from this study also showed that these entrapped swimmers were more likely to experience burnout when compared with the swimmers who did not feel entrapped.

Self-determination theory. Recently, a number of investigators (Cresswell \& Eklund, 2005a, 2005b, 2005c, 2007a, 2007b; Lemyre et al., 2007; Lemyre, Treasure, \& Roberts, 2006; Perreault et al., 2007) have applied self-determination theory to sport burnout. Self-determination theory contends that individuals have three basic psychological needs (autonomy, competence, and relatedness); when these needs are met, an individual's motivation is optimized and their psychological well-being is maximized (Deci \& Ryan, 1985). Consistent with the predictions of self-determination theory, these investigators posit that athletes who feel competent, autonomous, and related to significant others will experience lower levels of burnout. In an effort to investigate this, Perreault et al. (2007) conducted a study with 259 student-athletes from a Canadian sports school. Support was found for the hypothesis that the satisfaction of the basic needs (autonomy, competence, and relatedness) is associated with lower levels of athlete burnout. Similar findings were noted in several studies with elite rugby players (Cresswell \& Eklund, 2005a, 2005b, 2005c, 2007a, 2007b; Lemyre, Hall, \& Roberts, 2008; Lemyre et al., 2007), showing that self-determined forms of motivation are negatively related to athlete burnout. Because the samples from most of these studies were typically 
characterized by low levels of burnout, caution must be taken in generalizing these findings.

Engagement approach. The engagement approach to burnout was recently forwarded by Lonsdale and his colleagues (Lonsdale et al., 2007; Lonsdale, Hodge, $\&$ Raedeke, 2007). These researchers argued that engagement in sport is comprised of confidence, dedication, and vigor; also, it was suggested that engagement in sport is the opposite of burnout, so that a person who is fully engaged in sport is the polar opposite of the burned-out athlete. In a study with elite athletes from New Zealand, Lonsdale and his colleagues (2007) tested this approach and found that, as predicted, burnout and engagement scores were negatively related, suggesting that the constructs are polar opposites.

Although the initial results support the prediction that engagement is the polar opposite of burnout, additional studies are warranted. It should be noted that theoretically precise predictions about how engagement or the lack of engagement leads to burnout have not been made. As for future research, the authors concluded that "the most prudent course of action would be to examine athlete engagement as a separate higher-order construct; but one that may have important relationships with athlete burnout" (Lonsdale et al., 2007, p. 486).

\section{Frequency of Burnout}

Burnout has been a term popularized in the media, so much so that when interviewing athletes, researchers often do not use the term burnout because of the attached stigma. It is surprising, then, that more attention has not been paid to tracking the frequency that athletes experience burnout. Only one original estimate was made in a review by Gould and Dieffenbach (2002), in which data were used from a swimming investigation conducted by Raedeke (1997). In this study, it was estimated that $3 \%$ of athletes experience burnout.

Although not looking at burnout per se, some of the original negative trainingstress research conducted on Atlantic Coast Conference athletes by Silva (1990) showed that $66 \%$ of athletes felt some overtraining, with almost $50 \%$ indicating that it was a bad experience. Other research found that $60 \%$ of females and $64 \%$ of males had at least one episode of staleness in their running careers (Morgan, O’Connor, Sparling, \& Pate, 1987; Morgan, O'Connor, Ellickson, \& Bradley, 1988). Finally, Raglin and Morgan (1989) found that for swimmers who felt staleness during their freshman year of college, over $90 \%$ of these swimmers became stale in a subsequent collegiate year.

A recent study by Gustafsson et al. (2007) had 980 adolescent elite athletes (ages 17-21) complete the Eades Burnout Inventory. It was found that between 1 and $9 \%$ of female athletes and $2-6 \%$ of male athletes experienced symptoms of high level burnout (scored in the upper third of the subscales of negative selfconcept of athletic ability, devaluation by coach and teammates, psychological withdrawal/devaluation, and emotional and physical exhaustion). When the most stringent criteria for severe burnout were examined (top third of distribution on all four subscales), 1-2\% of the athletes fell into this category. Since the athletes studied were considered to be junior elite athletes, the authors suggested that the 
incidence rate would be even higher in senior elite competitors, although this has not yet been studied.

Finally, an inherent problem with all the attempts to identify the frequency of burnout in athletes is that different methods of measuring burnout and burnoutrelated states have been used. In addition, clear and empirically accepted criteria of what signifies burnout have not been developed. Any results from initial attempts to measure the frequency of burnout, then, must be viewed cautiously.

\section{Factors Associated With Athlete Burnout}

A topic of considerable interest to burnout researchers has been the identification of factors associated with athlete burnout. These factors were best summarized in a review article by Goodger and her colleagues (2007), where 61 published studies were identified with 27 studies specifically focusing on athletes. Correlates to burnout were recognized in the review and were divided into psychological correlates and demographic and situational correlates.

\section{Psychological Correlates}

Goodger and her colleagues (2007) identified 5 major themes characterizing the psychological correlates of burnout in athletes: motivation; coping with adversity; responses to training and recovery; the role of significant others; and athlete identity. Motivational correlates coming from the research focused on the types of motivation and motivation loss as well as enjoyment and perceptions of control. In general, a loss of motivation, lower enjoyment, and a perceived lack of control were associated with athlete burnout. Interestingly, the extrinsic motivationburnout relationship was less clear, with some studies showing little relationship and others demonstrating a strong negative association. One thing that was clear from these studies was the high correlation between burnout and changes in motivation. This significant finding leads to the question of whether changes in motivation are a result of the burnout process or a cause of burnout in athletes. Lemyre et al. (2008) tried to answer this question in their recent study, concluding that burnout in athletes may not simply be "motivation gone awry" but a consequence of athletes exhibiting maladaptive motivational dispositions related to their perceptions of ability, their tendencies for defining success, and the performance standards that they set.

The second theme resulting from the Goodger et al. (2007) review was coping with adversity. In all of the studies that were reviewed, increased stress was associated with higher levels of burnout. High trait anxiety, a personality disposition, was also positively correlated with burnout in athletes, suggesting that high trait anxious athletes (athletes who perceive competition as more threatening) are more susceptible to burnout. As one might expect, the athlete's ability to effectively cope with stress and adversity has been shown to be negatively associated with burnout.

Another psychological correlate of burnout that was identified by Goodger et al. (2007) was the athlete's responses to training and recovery. In this theme, overtraining was found to be related to greater mood disturbance and burnout. In 
addition, Kellmann and Gunther (2000) demonstrated that recovery strategies are negatively associated with athlete burnout, which highlights that fact that the prevention of burnout is not only about limiting the volume and intensity of training, but also about optimizing the athlete's recovery strategies.

The role of significant others is a fourth theme that characterizes the correlates of burnout. Coaches and parents have been the two sets of individuals that were examined in this regard. Goodger et al. (2007) indicated that studies examining the relationships between coaches and parents and burnout have been mixed, and it is not possible to make a general conclusion at this time. At first glance, one might expect a positive relationship between athlete burnout and the influence of parents and coaches, including the pressure to perform, unrealistic expectations, and criticism, since these factors may be interpreted as stressors. However, parents and coaches can also provide critical social support, which would be thought to reduce stress and burnout. These two contrasting views demonstrate the inability to reach a simplistic conclusion about the relationships between athlete burnout and parents and coaches; therefore, the specific behaviors emitted by these individuals must be further examined.

The final theme recognized by Goodger et al. (2007) that characterizes the psychological correlates of burnout in athletes is athletic identity, which has been examined by several investigators. The review by Goodger and her associates (2007) showed that there were too few studies to draw definitive conclusions. However, the literature that did exist at the time of their review generally showed a positive association between narrow athletic identity and burnout. Moreover, in their recent test of Coakley's (1992) model predictions, Black and Smith (2007) found that lower athletic identity exclusivity predicted reduced athletic accomplishments burnout subscale scores. Athletic identity exclusivity was also found to interact with other factors (e.g., perceived control) to predict sport devaluation burnout subscores.

In addition to the psychological correlates identified by Goodger et al. (2007), more recent studies have identified several other personality variables associated with athlete burnout. In several investigations (Chen, Kee, Chen, \& Tsai, 2008; Gould, Udry, Tuffey, \& Loehr, 1996; Hill, Hall, Appleton, \& Kozub, 2008), perfectionism has been associated with athlete burnout. In a study with 320 collegiate athletes, Chen et al. (2008) found that maladaptive perfectionism was associated with burnout while adaptive perfectionism was not. This is consistent with the earlier research of Gould et al. (1996). These findings also make intuitive sense, because of the high standards held by adaptive perfectionists, their high need for organization, and their low concern for mistakes and other evaluation. In contrast, maladaptive perfectionist have a high concern for mistakes and other evaluation along with their high standards and organization. This translates into consistent high standards for maladaptive perfectionists along with constant worry about achieving these standards and an overwhelming concern for the opinions of others. All in all, this is a deadly combination.

In addition to perfectionism, Chen, Kee, and Tsai (2008) examined the relationship between dispositional optimism and athlete burnout in young volleyball players. These results revealed that optimism was negatively associated with athlete burnout. 


\section{Demographic and Situational Correlates}

Much less research has been conducted on the situational and demographic correlates of athlete burnout (Goodger et al., 2007). Only one situational variable has been associated with burnout: athletes' training load or volume. According to Goodger et al. (2007) the majority of studies have shown a positive relationship between training volume and the levels of athlete burnout.

\section{Consequences of Burnout in Athletes}

It is somewhat surprising that researchers have paid so much attention to the correlates of burnout but much less attention to its consequences. Part of the reason for this is that most burnout measures include subscales that assess the short-term outcomes of athlete burnout: physical and emotional exhaustion; depersonalization; and a reduced sense of accomplishment. However, few studies have examined the long-term or the ultimate consequences of the burnout process. When an athlete becomes burned out and depersonalizes, does that affect their relationships with teammates, coaches, and family and friends? Are any of these changes permanent? Interestingly, in some of the original studies of burnout, Gould and his colleagues $(1996,1997)$ found that while some athletes permanently drop out of their sport, others drop in and out. Raedeke's (1997) work also demonstrates the feelings of entrapment that some athletes experience. If this is the case, how does this influence the athlete's long-term view of their sport experience and their athletic careers? In addition, how might physical and emotional exhaustion influence the student-athlete outside of his or her sport?

These questions demonstrate the lack of knowledge about the consequences of burnout in sport. Ultimately, understanding the long-term consequences of burnout may have some of the most important implications for athletes.

\section{Future Directions in Burnout Research}

Research on athlete burnout has significantly progressed since Ron Smith (1986) wrote his original review article over 20 years ago. At that time, we had no sport specific-studies on the topic, whereas today, we have over 30 studies focused solely on athlete burnout. A number of theories have also been developed, leading to a broadened understanding of the phenomenon. However, while considerable empirical and theoretical progress has been made, our knowledge base is, at best, in its early adolescence. Additional research is needed, and if we are to advance knowledge on this topic, the researchers must ask the right questions and use the most appropriate methods. Several directions for future research are outlined below.

A significant weakness of the existing burnout research is that much of it is based on participants who were not burned out (Cox, Tisserand, \& Taris, 2005; Goodger et al., 2007). For example, in the study by Perreault et al. (2007) that was designed to test the relationship between psychological need satisfaction and athlete burnout, significant relationships were found between basic need satisfaction and athlete burnout. However, the 259 participating athletes averaged very low 
burnout scores (on five point burnout scales: $M$ reduced sense of accomplishment $=1.92 ; M$ devaluation $=1.62 ; M$ exhaustion $=2.16 ; M$ total burnout $=1.90)$. Hence, few of the athletes sampled were experiencing burnout scores in the upper half of the scales. Because of the overwhelming reliance on healthy participants in this and other studies, there is a risk of confusing burnout responses with stress responses, especially at the lower levels of burnout. If researchers are truly interested in studying athlete burnout, then burned out athletes must identified and studied. Of particular importance are the large scale studies that would establish norms to help operationalize burnout. Given the purpose of this review, it is also especially important to assess burnout in collegiate athletes because of their efforts to not only perform at the highest levels athletically but simultaneously pursue academic degrees full time.

A second line of future research needs to explore the development of burnout over time (Goodger et al., 2007), carefully tracking burnout and motivation measures along with stress and recovery. An excellent initial study in this regard was conducted by Gustafsson et al. (2007), who studied the process of burnout in three elite cross-country skiers who had left their sport due to burnout. While the interviews were retrospective in nature, training logs from across the season were studied, and all three athletes were characterized by early skiing success that led to high expectations. In addition, the results revealed that the burnout process evolved with different severity and at different rates. All three athletes were characterized by a lack of mental and physical recovery. Moreover, the athletes did not engage in extraordinary amounts of physical training, but the intensity of training was very high.

A true longitudinal study was conducted by Cresswell and Eklund (2007b), who interviewed New Zealand rugby players multiple times over a full year. At some course of the season, 7 of the 9 players reported experiences that were consistent with burnout in the existing literature. In particular, the players reported physical and emotional exhaustion, sport devaluation, and reduced accomplishments. The findings were also consistent with these notions of burnout: stress based; sport commitment; entrapment; and self-determination theory.

These longitudinal studies seem to be especially useful in understanding burnout in athletes. Prospectively following athletes across time in a true longitudinal fashion using quantitative and qualitative stress, burnout, motivation, training volume, and stress and recovery assessments will be especially useful in future studies. An especially interesting longitudinal study would be to look at university athletes who are not only pursuing athletic success but academic success as well. It would be useful if such studies would track athletes both in and out of season and across years of college sports eligibility, looking at burnout effects in and out of the athletic context.

Looking at multiple theoretical perspectives of burnout simultaneously is another important area for future study. For example, this review has shown that different theoretical models of burnout have been forwarded in the literature, but most studies simply test just one model or theory. We need to determine the unique contributions of each theory and the degree with which they overlap in their predictions; simultaneous tests of multiple theories would allow us to do this.

Closely associated with the idea of looking at multiple theories is a multivariate approach to studying burnout. As previously stated, Gustafsson et al. (2007) 
found that the amount of training did not correlate with burnout levels in athletes but the intensity of training did. If the training volume was measured without an intensity assessment, we would not know this. Assessing physical training and rest-recovery practices in more detailed fashion is certainly needed. Similarly, theories of burnout focus on a range of diverse variables: training volume and intensity; stress and physical, social, and emotional recovery strategies; personality dispositions like maladaptive perfectionism, perceptions of control, motivational climate, performance expectations, and athletic identity; and adult control over sport decisions and choices. Looking at all of these variables simultaneously, especially in a longitudinal fashion, would be very useful. For example, a study of 182 age group swimmers by Black and Smith (2007) found support for Coakley's (1992) predictions that athletic identity exclusivity and perceived control over swimming significantly contributed to athlete burnout but did not moderate the stress-burnout relationship. This suggests that these variables may have independent contributions to explaining levels of athlete burnout.

Lastly, future investigators need to focus more attention on the consequences of burnout beyond the athlete's time in sport (e.g., health, depression, academic performance). In a study of burnout in junior tennis players, for instance, Goodger et al. (2007) found that some of the participants had negative reflections on their playing careers and their involvement in sport that continued to affect them after leaving tennis. In a similar vein of research, if college athletes become burned out as manifested in physical and emotional exhaustion, it would be interesting to determine if this is carried off of the field, potentially influencing their studies and their relationships with significant others.

\section{Implications for College Athletes and Athletics}

While we certainly need more research on burnout in athletes, this does not mean that the current research does not have implications for NCAA athletes, coaches, and support personnel. First, athletic personnel need to realize that different severities (Gustafsson et al., 2007) and strains of burnout (Gould, Tuffey, Udry, \& Loehr, 1997) exist. Not everyone who burns out will discontinue sports involvement - indeed, some are entrapped. Others most likely burnout for a short time and then recover in the off season. It has also been found that different strains of burnout exist. Some burnout seems to be more physically driven, most likely resulting from training volumes that are too intense and a lack of physical and mental recovery. Other strains seem to be driven more by excessive expectations placed on athletes and a lack of control and decision making given to the athletes. This might be exacerbated by the increasing pressure associated with elite college sports and athletic departments' needs to field winning teams that can fill stadiums and help offset raising costs. Lastly, some student-athletes (most likely maladaptive perfectionistic individuals, athletes who base their self-esteem on their athletic identity, which is focused exclusively on sport, and those who experience high degrees of early success) may be at risk for developing burnout. Athletic staff must be familiar with these strains and symptoms and actively work to monitor the athletes with whom they interact. 
Often, when people think of athlete burnout, they think of excessive training and training loads. While there are certainly cases of burnout that are caused by overtraining and under recovering, several studies (Gould et al., 1997; Gustafsson et al., 2007) have shown that it may not be the volume of training that is a problem, but the intensity of the training, coupled with a lack of recovery. In addition, this recovery may need to take several forms: physical; emotional; and social.

When it comes to practical implications, the importance of coaches and athletic support staff education is paramount. It is ironic that most NCAA programs require little sport science and medicine training for coaches, and it is commonly joked that the requirements to coach in America simply include the possession of a warm-up and a whistle and, of course, a winning record. However, the NCAA should explore a variety of coaching and support staff educational efforts. Online education, podcasts, and seminars at NCAA championships and coach's meetings seem warranted. Along with overall training programs for collegiate coaches, there is a special need to better educate coaches about periodized training, with a special emphasis placed on stress and recovery methods (See Kellmann, 2000). From a coach's perspective, the appealing aspect of stress and burnout education is that a solid understanding of these topics can lead to increased performance, as well as improvement of the athlete's general health. Therefore, even the most competitive coaches should be receptive to burnout-related information because it can lead to better outcomes on the field of play.

Yet another way for the NCAA to help prevent burnout in athletes would be athlete education on topics such as periodized training, stress management, recovery, nutrition, and the importance of having balance in one's life. This might be couched under a "science of winning" label, which would most likely appeal to most athletes, but along with information about enhancing one's performance, the NCAA could convey information aimed at teaching health-related behaviors via sport. Such information could be conveyed on an NCAA "science of winning" website, where athletes could access information or even courses offered by exercise and sport science and kinesiology academic departments. In addition, this information could be distributed through podcasts, which may appeal to the technology-centered student-athlete of today. By developing these vehicles for disseminating burnout prevention and other sport science-related information, the NCAA would help to close the athletic-academic divide, which has been a growing concern on many college campuses.

\section{References}

American Medical Association. (1966). Standard nomenclature of athletic injuries. Chicago, IL: American Medical Association.

Black, J.M., \& Smith, A.L. (2007). An examination of Coakley's perspectives on identity, control, and burnout among adolescent athletes. International Journal of Sport Psychology, 38, 417-436.

Bowen, W.G., \& Levin, S.A. (2003). Reclaiming the game: College sports and educational values. Princeton, NJ: Princeton University Press.

Chen, L.H., Kee, Y.H., Chen, M., \& Tsai, Y. (2008). Relation of perfectionism with athletes' burnout: Further examination. Perceptual and Motor Skills, 106, 811-821. 
Chen, L.H., Kee, Y.H., \& Tsai, Y. (2008). Relation of dispositional optimism with burnout in athletes. Perceptual and Motor Skills, 106, 693-698.

Coakley, J. (1992). Burnout among adolescent athletes: A personal failure or social problem? Sociology of Sport Journal, 9, 271-285.

Cox, T., Tisserand, M., \& Taris, T. (2005). The conceptualization and measurement of burnout: Questions and directions. Work and Stress, 19, 187-191.

Deci, E.L., \& Ryan, R.M. (1985). Intrinsic motivation and self-determination in human behavior. New York: Plenum.

Cresswell, S.L., \& Eklund, R.C. (2005a). Changes in athlete burnout and motivation over a 12-week league tournament. Medicine and Science in Sports and Exercise, 37, 1957-1966.

Cresswell, S.L., \& Eklund, R.C. (2005b). Motivation and burnout among top amateur rugby players. Medicine and Science in Sports and Exercise, 37, 469-477.

Cresswell, S.L., \& Eklund, R.C. (2005c). Motivation and burnout in professional rugby players. Research Quarterly for Exercise and Sport, 76, 370-376.

Cresswell, S.L., \& Eklund, R.C. (2006). Athlete burnout: Conceptual confusion, current research, and future directions. In S. Hanton \& S. S, Mellaleu (eds.), Literature reviews in sport psychology (pp. 91-129). New York: Nova Science.

Cresswell, S.L., \& Eklund, R.C. (2007a). Athlete burnout: A longitudinal study. The Sport Psychologist, 21(1), 1-20.

Cresswell, S., \& Eklund, R.C. (2007b). Athlete burnout and organizational culture: English rugby replication. International Journal of Sport Psychology, 38, 365-387.

Ericsson, K.A. (1996). The road to excellence: The acquisition of expert performance in the arts and sciences, sports and games. Mahwah, NJ: Erlbaum.

Goodger, K., Gorely, T., Lavalle, D., \& Harwood, C. (2007). Burnout in sport: A systematic review. The Sport Psychologist, 21(2), 125-149.

Gould, D., \& Dieffenbach, K. (2002). Overtraining, under recovery and burnout in sport. In M. Kellmann (Ed.), Enhancing recovery: Preventing underperformance in athletes (pp. 25-35). Champaign, IL: Human Kinetics.

Gould, D., Tuffey, S., Udry, E., \& Loehr, J. (1996). Burnout in competitive junior tennis players. II: Qualitative analysis. The Sport Psychologist, 10, 341-366.

Gould, D., Udry, E., Tuffey, S., \& Loehr, J. (1996). Burnout in competitive junior tennis players. I: A quantitative psychological assessment. The Sport Psychologist, 10, 322340.

Gould, D., Tuffey, S., Udry, E., \& Loehr, J. (1997). Burnout in competitive junior tennis players, III. Individual differences in the burnout experience. The Sport Psychologist, 11, 257-276.

Gustafsson, H., Kentta, G., Hassmen, P., \& Lundquist, C. (2007). Prevalence of burnout in adolescent competitive athletes. The Sport Psychologist, 21, 21-27.

Gustafsson, H., Kentta, G., Hassmen, P., Lundquist, C., \& Durand-Bush, N. (2007). The process of burnout: A multiple case study of 3 elite endurance athletes. International Journal of Sport Psychology, 38, 388-416.

Hill, A.P., Hall, H.K., Appleton, P.R., \& Kozub, S.A. (2008). Perfectionism and burnout in junior elite soccer players: The mediating influence of unconditional self-acceptance. Psychology of Sport and Exercise, 9, 630-644.

Kellmann, M. (2000) (Ed.). Enhancing recovery: Preventing underperformance in athletes. Champaign, IL: Human Kinetics.

Kellmann, M., \& Gunther, K. (2000). Changes in stress and recovery in elite rowers during preparation for the Olympic Games. Medicine and Science in Sports and Exercise, $35,676-683$.

Kentta, G., \& Hassmen, P. (1998). Overtraining and recovery: A conceptual model. Sports Medicine (Auckland, N.Z.), 1, 1-16. 
Kentta, G., Hassmen, P., \& Raglin, J.S. (2001). Training practices and overtraining syndrome in Swedish age-group athletes. International Journal of Sports Medicine, 22, 460-465.

Lemyre, P.N., Hall, H.K., \& Roberts, G.C. (2008). A social cognitive approach to burnout in elite athletes. Scandinavian Journal of Medicine \& Science in Sports, 18, 221-234.

Lemyre, P.N., Roberts, G.C., \& Stray-Gundersen, J. (2007). Motivation, overtraining, and burnout: Can self-determined motivation predict overtraining and burnout in elite athletes? European Journal of Sport Science, 7, 115-126.

Lemyre, P.N., Treasure, D.C., \& Roberts, G.C. (2006). Influence of variability in motivation and affect on elite athlete burnout susceptibility. Journal of Sport \& Exercise Psychology, 28, 32-48.

Lonsdale, C., Hodge, K., \& Jackson, S.A. (2007). Athlete engagement: II. Development and initial validation of the Athlete Engagement Questionnaire. International Journal of Sport Psychology, 38, 471-492.

Lonsdale, C., Hodge, K., \& Raedeke, T.D. (2007). Athlete engagement: I. A qualitative investigation of relevance and dimensions. International Journal of Sport Psychology, $38,451-470$.

Morgan, W.P., O’Connor, P.J., Ellickson, K.A., \& Bradley, P.W. (1988). Personality structure, mood states, and performance in elite distance runners. International Journal of Sport Psychology, 19, 247-269.

Morgan, W.P., O'Connor, P.J., Sparling, P.B., \& Pate, R.R. (1987). Psychologic characterization of the elite female distance runner. International Journal of Sports Medicine, 8, S124-131.

NCAA. (2007, January 2). President's message-Yeah, but facts show student-athletes outperform in class. Retrieved April 15, 2009, from http://www.ncaa.org/wps/ ncaa?ContentID $=258$

Perreault, S., Gaudreau, P., Lapointe, M-C., \& Lacroix, C. (2007). Does it take three to tango? Psychological need satisfaction and athlete burnout. International Journal of Sport Psychology, 38, 437-450.

Raedeke, T.D. (1997). Is burnout more than stress? A sport commitment perspective. Journal of Sport \& Exercise Psychology, 19, 396-417.

Raglin, J.S., \& Morgan, W.P. (1989). Development of a scale to measure training-induced distress. Medicine and Science in Sports and Exercise, 21(Suppl), 60.

Schmidt, G.W., \& Stein, G.L. (1991). Sport commitment: A model integrating enjoyment, dropout, and burnout. Journal of Sport \& Exercise Psychology, 13, 254-265.

Silva, J.M. (1990). An analysis of the training stress syndrome in competitive athletics. Journal of Applied Sport Psychology, 2, 5-20.

Smith, R.E. (1986). Toward a cognitive-affective model of athlete burnout. Journal of Sport Psychology, 8, 26-50.

Weinberg, R.S., \& Gould, D. (2007). Foundations of sport and exercise psychology (4th ed.). Champaign, IL: Human Kinetics. 